\title{
Carolyn Merchant, The Anthropocene \& the Humanities: From Climate Change to a New Age of Sustainability
}

\author{
New Haven, CT: Yale University Press, 2020. Pp. 232. ISBN: 978-0- \\ 3002-4423-6. \$26.00 (hardback).
}

\author{
Emily Hayes \\ Oxford Brookes University
}

With The Anthropocene \& the Humanities: From Climate Change to a New Age of Sustainability Carolyn Merchant, professor emerita of environmental history, philosophy and ethics at the University of California, Berkeley, aims to deepen understandings of the mutual shaping of the Anthropocene and environmental humanities. The latter, the author claims, has devoted less attention than economics, politics and historical studies to the apprehended environmental issues and climate change.

The intended readership for this work needs to be stated straight up. Although written for 'an educated public' of reading clubs, 'undergraduate courses and graduate seminars' (p. xi), The Anthropocene \& the Humanities read, to me, like a high-school- and early undergraduate-level take on human-made climate change, industrial capitalist economies and their depictions in art and literature. The work's geographical bias, by no means an inherent fault, should have been flagged up; the perspective it is written from, and the putative readership it is intended for, are North American. This is because the aforementioned undergraduates are the sorts of students who, in the US, study in liberal-arts colleges or take comparative-literature courses whilst intending to pursue science majors. Such constituencies have shaped the choices Merchant has made.

The intention of this book is to demonstrate how the concept of the Anthropocene goes beyond earlier concepts and periodizations such as preindustrial, colonial, industrial, modern and postmodern by presenting a clear and forceful characterization of the future crisis humankind faces' ( $p . x i$ ) and to illustrate its impact upon literature, art and philosophy, and to a lesser extent the law. The six short chapters are scaled for the designated readership. The narrative is paced to allow for non-expert readers to absorb this important argument. The temporal scope of the book ranges from circa the sixth century BC to the present. Its spatial scope is predominantly northern-hemisphere and anglophone.

Chapter 1 surveys the definition of the Anthropocene formulated by Paul Crutzen and Eugene Stoermer and the key figures and researchers who have advanced various conceptual terms inspired by the former. The book includes black-and-white images of the theorists whose ideas are discussed, from Donna Haraway to Dipesh Chakrabarty, Naomi Klein, Ian Angus, Eduardo Viveiros de Castro and Jason W. Moore. However, Greta Thunberg is missing from this line-up in a work purportedly aimed at younger readers. Surely she has impacted imaginations and the national environmental movements of the US?

(c) The Author(s), 2021. Published by Cambridge University Press on behalf of British Society for the History of Science. This is an Open Access article, distributed under the terms of the Creative Commons Attribution licence (https://creativecommons.org/ licenses/by/4.0/), which permits unrestricted re-use, distribution, and reproduction in any medium, provided the original work is properly cited. 
The next chapter details shifts in the spatial, scalar, social and material geographies of energy. Merchant steers us towards the topic of steam power, where we segue from Thomas Newcomen to the technical additions to the steam engine brought by James Watt, the keeper of instruments at the University of Glasgow, which, the author argues somewhat too teleologically, spawned the steamboat, the train, the factory, and the age of industrialization, spewing carbon dioxide from the burning of fossil fuels into the atmosphere' ( $p .45)$. She then moves on to French investigator of the motion of caloric heat Sadi Carnot; Polish-born mathematician and physicist Rudolf Clausius, one of many who contributed to elucidating thermodynamics; William Thomson; and Belgian theorizer of far-from-equilibrium thermodynamics Ilya Prigogine. Subsequent chapters revisit to varying degrees the centrality of energy production and distribution to the broader philosophical and ethical questions in play.

Art that characterizes the Anthropocene and the 'death of nature' resulting from the steam engine's impact (p. 45) are the subject of Chapter 3. Here surprises are few; Turner, Manet and Monet all figure. That is, until Merchant considers American artists. As well as American Progress (1872) by John Gast, black-and-white reproductions of paintings by Andrew Melrose and John Kane feature. The examination of the medium of photography and moving film, though narrow, intelligently links photographic images of enslaved persons constructing US railroads to the previous chapter. Although Merchant's belief is that artists can transform our conceptions of progress, her definition of 'artist' might be expanded. The documentation of a wider demographic of craftworkers, knowledge makers and consumer audiences who participated in this process could be more fully acknowledged. Further, artists and the art world have been, and continue to be, active in, and contributors to, past and contemporary Anthropocenic change. Merchant does not ask how art, or shifting human definitions of art and aesthetic appetites, have contributed to creating and shaping the Anthropocene as much as depicting it.

'Images could play a formative role in changing personal behaviour and public policy in the future. Viewing art could help to promote individual and collective action', claims Merchant (p. 65). This parallels the author's assertion that literature helps us to understand 'the human dimensions of the Anthropocene' (p. 189). Yet these claims cannot be sustained without sufficient criticism, or discussion, of what art forms have been historically and what they are currently deemed to be, worldwide. On their own, literary works can only do so much. The onus is on the reader and the intentions, training and context that they bring to reading a work. Writers whose lives and works readers might think they know, but likely do not, star in the chapter on literature. After discussions of Wordsworth and Dickens, Merchant addresses several US authors, including the usual suspects of the American transcendentalist movement. Aldo Leopold I knew of. However, thanks to Merchant, Nathaniel Hawthorne and Leo Marx have been bumped to the top of my reading wish list. The scope is decidedly Anglocentric. In conjunction, and despite nods to wider geographies, race, class and gender, the absence of numerous European novelists such as Emile Zola, Henrik Pontoppidan, Ivan Turgenev and Leo Tolstoy is felt as much as is that of examples of writers of non-fiction, including essayists, travel writers and diarists.

If the chapters on literature and art (to a lesser extent) are Anglocentric, then that on religion roves more widely. Interfaith action, Merchant emphasizes, has the potential to achieve great things for the environmental movement. Merchant presents several eco-Christian groups before supplying details of collaborative conferences and projects active in this area. Whilst I worry that the uptake of the environmental cause is just another way for such groups to empower themselves, it is obvious that the global behaviour change required to fight and prevent rising temperatures, pollution and environmental degradation must involve the collaboration of religious and faith groups as well as 
governments, economists, scientists and creative industries. The task of defining and locating the core belief of what we, each human being, in every country and community group, value most and what motivates us to empathize and care about (the first step towards caring for) something other than ourselves demands the participation of all. Christianity, described by the author as the religion of the poor and oppressed, is there on the front line of climate change. However, there are dangers, barely discussed here: Christian and imperial collusion is bypassed; eco-Christian groups' definition of life and perceptions of gender and its associated behaviours and roles also raise concerns. Anthropocenic activist and theologian Jay McDaniel's stirring rhetoric, inflected with creationist notes (pp. 103-5), may read as natural to some and disturbing to others. Further, non-human- and more-than-human-entity rights are not explained here. Questions therefore remain about how interfaith groups' involvement may impact women and their rights.

Arguably, Merchant distinguishes too rigidly between mainstream Judaeo-Christian religion and other faith systems and beliefs. Daoism and Hinduism are discussed, but without acknowledgement of Chinese and Indian environmental problems and policies. The brief nod to the rich spiritual philosophy of Islam comes in the form of a Moroccan project to install solar power panels on mosques (p. 105). Such a significant lacuna unbalances the chapter. As does the lack of discussion of shamanist and animist practices. Why were the Honduran indigenous group which cares for the forest and the Earth and 'faith communities [who] have rich language to address issues of ethics and justice' (p. 104) not further explored? In this chapter sections on the processual energy-based, or ecological, philosophy of twentieth-century thinkers such as Alfred North Whitehead and Charles Hartshorne anticipate the next chapter, which is dedicated to philosophy. Nevertheless, I asked myself whether there were not salient earlier examples of individuals who, though not philosophers in a professional sense, might have recorded their own wisdom and left traces of their inquiring minds.

The clever and playful chapter on philosophy distinguishes between information and knowledge, forms and ideals, and parallels between past and present philosophies via judicious reference to Rebecca Newberger Goldstein's Plato at the Googleplex: Why Philosophy Won't Go Away (2014). This illuminates the recursive connections and themes criss-crossing the book. The chapter is heavily centred on European, particularly Greek, thought (p. 125). Islamic, Chinese, Hindu and other philosophical traditions cannot just be subsumed under the previous focus on religion. In places, Merchant uses phrases such as 'modern' (pp. xi, 73, 119), 'modernity' (p. 17) and 'modernization' (p. 74) which are now frequently contested by scholars. When she feels that her intended early-stage reader might be ready, Merchant does concede the unfathomable, unpredictable, uncontrollable qualities of nature (pp. 121,125), but this might have presented sooner as one of the fundamentals of the whole work.

Does the work avoid the pitfalls of a narrow, elitist focus? Overall, not in terms of the art and literature. Nor the chapter on religion. However, this is redressed by the powerful sections which appear towards the end of this work in the chapter on ethics and justice. Here Merchant addresses how 'an Age of Sustainability and partnership between humanity and nature' must supersede the age of the Anthropocene and human control (p. 126). Skimming multicultural, ecological, anthropocentric and liberal philosophies, Merchant's partnership ethics elaborates a theory of human and non-human relations. With a view to helping readers move from the age of the Anthropocene to the Age of Sustainability, she presents a fivepoint ethical plan (p. 126). Merchant then introduces the ethical dimensions of environmental negotiations via a discussion of the ideas propounded by two US philosophers, Peter Singer and Stephen M. Gardiner, who, to my knowledge, are lesser known in the UK. Complementing this theoretical focus, the section on climate justice or 'environmental 
ethics "on the ground" (p. 135) outlines a number of African American and Native American activist groups' actions from the 1980s onwards. Notable here is the activism of the African American academic Robert Bullard, author of Confronting Environmental Racism (1993). The ethics chapter might have incorporated sections on case studies of indigenous beliefs and environmental anthropology studies from beyond the US; examples of colonial overexploitation and environmental holocaust might also have been discussed. The scattered references to global environmental policies might have been consolidated, especially now that the world waits for the Biden administration to make good on its promises to safeguard indigenous peoples threatened by petrochemical and gas industry resource exploitation and shift the US policy on planetary environmental, and climate, change.

The work's principal shortcoming, for me, is its lack of critical bite. Undoubtedly, in the Anthropocene 'much is at stake for the mutual survival of humanity and nature' (p. x). Yet this is, in my view, problematic. For as Merchant, the author of The Death of Nature (1980) who is decidedly modest about her own contributions to ecofeminism and histories of science here, has detailed elsewhere, the distinct concepts of nature and humanity, as formulated by some people in some parts of the world, set the conditions for Anthropocenic malpractices. Consequently, I could not help but wish that she had found the words and images with which to present the essential ontological entanglement of the two earlier on in the book. Contingently, sentences such as "[e]xperimentation and technology coupled with mathematics allowed humanity to change the planet for the benefit of the Anthropos' (p. 199) made me question Merchant's concept of 'humanity' and, elsewhere, that of 'humankind'. The early modern era cannot be characterized as consisting solely of experimentation, mechanics and maths. These practices alone do not account for the exploitation of peoples and environments. Humanity is not the problem in and of itself. Rather, certain factions of human beings exploited and unbalanced environments. More detail, and critical appraisal, are needed about who did what, where and when.

Questions of global governance are not shirked; Merchant boldly states the need for it. Yet several geographical issues arise concerning definitions of space and decisions as to where to dress disciplinary borders. Without doubt, the interdisciplinary turn to the 'environmental humanities', a term which Merchant celebrates, is vital. Yet readers should recall that the humanities, as a branch of knowledge, were as much a reflection of Anthropocenic processes as they have been agents in the Anthropocene. Far from being innocent bystanders, humanities subjects and their practitioners have also been implicated in the Anthropocene, perhaps to different degrees, and in other ways and places, than scientific practitioners. It is a distortion to imagine that science and humanities are distinct. This fiction is peddled by academics across the notional divide between the two fields, yet it is one which we need to divest ourselves of if we are to attain the goals of this work. In tandem with scientists and policy makers, the humanities will help to communicate and disseminate, as well as produce, scientific analyses of the causes and problems of, and solutions to, climate change and environmental problems. Understandings of the term 'humanities' need to become ethnically and geographically nuanced. It is the responsibility of future scholars to conceive of the tools, languages, images, concepts and behaviours required for this task. A wise place from which to begin might be to acknowledge the comparatively recent early nineteenth-century distinction made between arts, crafts and technical skills. ${ }^{1}$ It would also help to highlight

1 See Lydia Goehr, The Imaginary Museum of Musical Works: An Essay in the Philosophy of Music, Oxford: Clarendon Press, 1992; Howard Morphy, 'The anthropology of art', in Tim Ingold (ed.), The Companion Encyclopedia of Anthropology, London: Routledge, 1994, pp. 648-85. 
the persistent fallibility of contingent, experimental, partial, ongoing, incomplete, constantly mistake-making and self-correcting scientific practices.

Such criticisms are somewhat overstated. This book is written in clear, plain English and generally accessible with, perhaps, the exception of terms such as 'hubris' and 'ethics' which might be problematic for young readers or non-expert audiences. It deftly assembles useful examples for learners of all ages with little expertise in any one humanities subject or Anthropocene literatures. Merchant's predominantly anglophone and Eurocentric explorations form a cogent pathway towards understanding the core argument of this work. Each chapter highlights its limitations and suggests additional works for those who wish to follow up the individuals and ideas discussed. Recognizing the need to write wider, indeed global, histories of the Anthropocene, more than would most academics, Merchant owns the partiality of her text. This, doubtless unintentionally, sets up a distinction between the North and the South or the developed and the developing world. That said, the disclaimers at the end of each chapter can be regarded as a gift to teachers since they offer students signposts to follow up in debate and research projects. Complete bibliographic references and an index further serve this cause. This therefore has the potential to be an extremely useful book for teachers and students with imagination.

This review concludes with my own signposts. The first directs readers interested in this work towards studies of indigenous ethical partnerships detailed in environmental anthropology studies. These relate to the second signpost pointing towards geography, which since its academic professionalization in Britain and in European countries has attempted to bridge what were, in the nineteenth century, the emergent human and physical sciences, whilst also concerning itself with an array of graphic sources comprising texts and maps, charts, models, drawings and paintings, to name a few. The third will, I hope, impel readers to explore the wealth of Merchant's publications on ecofeminism, histories of the environment and science. 